\title{
Recommended cessation counselling for pregnant women who smoke: a review of the evidence
}

Cathy L Melvin, Patricia Dolan-Mullen, Richard A Windsor, H Pennington Whiteside, Jr, Robert L Goldenberg

\begin{abstract}
Objective-To review the evidence base underlying recommended cessation counselling for pregnant women who smoke, as it applies to the steps identified in the Agency for Healthcare Research and Quality's publication, Treating tobacco use and dependence: a clinical practice guideline.
\end{abstract}

Data sources-Secondary analysis of literature reviews and meta-analyses.

Data synthesis-A brief cessation counselling session of 5-15 minutes, when delivered by a trained provider with the provision of pregnancy specific, self help materials, significantly increases rates of cessation among pregnant smokers. This low intensity intervention achieves a modest but clinically significant effect on cessation rates, with an average risk ratio of 1.7 (95\% confidence interval 1.3 to 2.2$)$. There are five components of the recommended method-"ask, advise, assess, assist, and arrange".

Cecil G Sheps Center for Health Services Research, University of North

Carolina-Chapel Hill, Chapel Hill, North Carolina, USA

C L Melvin

Center for Health Promotion Research and Prevention,

University of

Texas-Houston Health

Science Center, School of Health, Houston,

Texas, USA

P Dolan-Mullen

Smoke-Free Families National Program Office, University of

Alabama at

Birmingham,

Birmingham,

Alabama, USA

R A Windsor

H P Whiteside Jr

R L Goldenberg

Correspondence to:

Cathy L Melvin, PhD, MPH,

Cecil G Sheps Center for

Health Services Research,

725 Airport Road, Campus

Box 7590 , University of
North Carolina-Chapel Hill,

Chapel Hill, NC 27599,

USA

cathy_melvin@unc.edu
Conclusions-We recommend these evidence based procedures be adopted by all prenatal care providers. The use of this evidence based intervention is feasible in most office or clinic settings offering prenatal care and can be implemented without inhibiting other important aspects of prenatal care or disrupting patient flow. If implemented widely, this approach has the potential to achieve an important reduction in a number of adverse maternal, infant, and pregnancy outcomes and to reduce associated, excess health care costs.

(Tobacco Control 2000;9(Suppl III):iii80-iii84)

Smoking cessation is one of the most important actions a woman can take to improve the outcome of her pregnancy. Despite the acknowledged harm associated with tobacco use during pregnancy for both mother and infant, ${ }^{12}$ a large proportion of pregnant women continues to smoke. Although some women stop smoking once they learn they are pregnant, the majority do not. Therefore, the implementation of an effective smoking cessation intervention would have a significant impact on the health of mothers and children.
Keywords: smoking cessation; pregnancy
Data sources

To develop consensus on a best practice intervention for pregnant smokers, we reviewed the evidence related to cessation counselling during pregnancy in the published literature ${ }^{3-7}$ (table 1), including the evidence supporting the Agency for Health Care Policy and Research's (AHCPR) clinical practice guideline, Smoking cessation, ${ }^{89}$ and its recent update, Treating tobacco use and dependence: a clinical practice guideline, by the Agency for Healthcare Research and Quality (AHRQ, formerly AHCPR). ${ }^{10} \mathrm{~A}$ panel of experts also considered this literature and its implications for a best practice intervention at the 1998 consensus workshop on smoking cessation in pregnancy, sponsored by the Robert Wood Johnson Foundation's Smoke-Free Families Program, the Health Resources and Services Administration, and the Centers for Disease Control and Prevention. Participants included representatives from the American Cancer Society, the National Cancer Institute, the National Heart, Lung, and Blood Institute, the Association of Maternal and Child Health Programs, the Oklahoma Health Care Authority, the Partnership for Prevention, and the Addressing Tobacco in Managed Care initiative. The panel considered three questions: (1) is pregnancy an appropriate time for smoking cessation efforts?; (2) are interventions effective?; and (3) how can smoking cessation interventions be introduced into health systems?

The panel concluded that pregnancy is an appropriate time to achieve smoking cessation and that successful interventions produce clear, short term, and cost effective benefits. They also concluded that a brief cessation counselling session can improve cessation rates as compared to simple advice to quit, and that more intensive counselling has not been documented to increase cessation rates among pregnant smokers. Furthermore, they found that almost all benefits of brief counselling occur in light to moderate smokers.

\section{Data synthesis}

Based on these reviews of the evidence, we recommend a simple approach that has been shown to increase cessation in prenatal populations as compared to usual advice to stop smoking. A brief cessation counselling session of 5-15 minutes, when delivered by a trained provider with the provision of pregnancy specific, self help materials, 
Table 1 Settings, interventions, smoking cessation and risk ratios (95\% confidence intervals) for 16 trials

\begin{tabular}{|c|c|c|c|c|c|c|c|}
\hline \multirow[b]{2}{*}{ Trial } & \multirow[b]{2}{*}{ Setting } & \multirow[b]{2}{*}{ Intervention } & \multicolumn{2}{|c|}{ Treatment } & \multicolumn{2}{|c|}{ Control } & \multirow{2}{*}{$\frac{\text { Risk ratio }}{(95 \% C I)}$} \\
\hline & & & $n$ & $\%$ & $n$ & $\%$ & \\
\hline Sexton, Hebel $1984^{16}$ & $\begin{array}{l}\text { Private }+ \text { university } \\
\text { clinics (US) }\end{array}$ & $\begin{array}{l}\text { One or more personal visits, monthly phone contact with } \\
\text { master's level educator }+ \text { biweekly mailed materials }\end{array}$ & 389 & 31.9 & 392 & 6.9 & $4.6(3.1$ to 6.8$)$ \\
\hline Winsdor et al $1985^{17}$ & Public clinics (US) & $\begin{array}{l}10 \text { minute session with bachelor's level counsellor + materials } \\
+ \text { manual }\end{array}$ & 102 & 13.7 & 104 & 1.9 & $7.1(1.7$ to 30.6$)$ \\
\hline Ershoff et al $1989^{12}$ & HMO (US) & Brief counselling by health educator +8 booklets mailed weekly & 126 & 26.2 & 116 & 17.2 & $1.5(0.9$ to 2.5$)$ \\
\hline Burling et al $1991^{18}$ & $\begin{array}{l}\text { Urban hospital clinic } \\
\text { (US) }\end{array}$ & Personal letter from chief of prenatal clinic + pamphlet & 70 & 12.8 & 69 & 5.8 & $2.2(0.7$ to 6.8$)$ \\
\hline Hjalmarson et al $1991^{19}$ & Public clinics (Sweden) & Self help manual distributed by obstetrician & 444 & 12.6 & 209 & 8.6 & $1.5(0.9$ to 2.4$)$ \\
\hline Price et al $1991^{20}$ & $\begin{array}{l}\text { Urban hospital clinic } \\
\text { (US) }\end{array}$ & $\begin{array}{l}\text { Videotape }+ \text { pamphlet }+ \text { brief counselling with health } \\
\text { educator or booklet }+ \text { counselling }\end{array}$ & 123 & 4.9 & 70 & 1.4 & $3.4(0.4$ to 27.8$)$ \\
\hline O'Connor et al $1992^{21}$ & $\begin{array}{l}\text { Group practice } \\
\text { (Canada) }\end{array}$ & $\begin{array}{l}20 \text { minute counselling by public health nurse }+ \text { manual }+ \\
\text { phone contact }\end{array}$ & 90 & 13.3 & 84 & 6.0 & $2.2(0.8$ to 6.1$)$ \\
\hline Peterson et al $1992^{22}$ & HMO (ÚS) & Mailed manual + audiotape & 43 & 16.3 & 47 & 17.0 & $1.0(0.4$ to 2.4$)$ \\
\hline Windsor et al $1993^{12}$ & Public clinics (US) & $\begin{array}{l}15 \text { minute counselling by educator }+ \text { manual }+ \text { clinic } \\
\text { reinforcement }+ \text { mailed letter }+ \text { "buddy" support methods }+ \\
\text { quarterly newsletter }\end{array}$ & 400 & 14.2 & 414 & 8.4 & $1.7(1.1$ to 2.5$)$ \\
\hline $\begin{array}{l}\text { Secker-Walker et al } \\
1994^{23}\end{array}$ & University clinic (US) & $\begin{array}{l}\text { Counselling by trained counsellors at } 1 \text { st } 3 \text { visits and at } 36 \\
\text { weeks }+ \text { booklet }\end{array}$ & 136 & 10.3 & 176 & 8.5 & $1.2(0.6$ to 2.6$)$ \\
\hline Kendrick et al $1995^{24}$ & Public clinics (US) & 1-5 minute counselling at multiple visits & 233 & 8.2 & 284 & 9.2 & $0.9(0.5$ to 1.6$)$ \\
\hline Kendrick et al $1995^{24}$ & $\begin{array}{l}\text { Public clinics + WIC } \\
\text { sites (US) }\end{array}$ & Brief counselling + material & 307 & 7.2 & 546 & 5.1 & $1.4(0.8$ to 2.4$)$ \\
\hline Kendrick et al $1995^{24}$ & $\begin{array}{l}\text { Public clinics + WIC } \\
\text { sites (US) }\end{array}$ & $\begin{array}{l}6 \text { minute counselling in prenatal visits; } 1-2 \text { minute counselling } \\
\text { at WIC sites }\end{array}$ & 348 & 3.7 & 347 & 4.3 & $0.9(0.4$ to 1.8$)$ \\
\hline Hartmann et al $1996^{15}$ & University clinic (US) & $\begin{array}{l}\text { Brief counselling by trained resident to set goals }+ \text { material }+ \\
\text { CO testing; goal setters contacted by volunteer }\end{array}$ & 107 & 20.0 & 100 & 10.0 & $2.0(1.0$ to 4.0$)$ \\
\hline Walsh et al $1997^{25}$ & Public clinic (Australia) & $\begin{array}{l}\text { Brief advice by doctor }+14 \text { minute videotape }+10 \text { minute } \\
\text { counselling by midwife }+ \text { manual }\end{array}$ & 127 & 9.0 & 125 & 0.0 & $2.4(1.0$ to 5.6$)$ \\
\hline Gielen et al $1997^{26}$ & University clinic (US) & $\begin{array}{l}\text { Guide }+15 \text { minute counselling by trained layperson }+ \text { materials } \\
\text { for support person }+ \text { clinic staff reinforcement and support }\end{array}$ & 193 & 6.2 & 198 & 5.6 & $1.1(0.5$ to 2.5$)$ \\
\hline
\end{tabular}

Summary risk ratio (random effects model) $=1.7(1.3$ to 2.2$)$

Reprinted with permission from WB Saunders Co. Mullen PD. Maternal smoking during pregnancy and evidence- based intervention to promote cessation. In: Spangler JG, ed. Primary care: clinics in office practice (tobacco use and cessation). Philadelphia: WB Saunders, 1999:26:577-89.

significantly increases rates of cessation among pregnant smokers. ${ }^{11}$ A previous meta-analysis has found that this low intensity intervention achieves a modest but clinically significant effect on cessation rates, with an average risk ratio across the 16 studies (weighted by the precision of each study's risk ratio) of 1.7 , and a $95 \%$ confidence interval $(95 \% \mathrm{CI})$ of 1.3 to $2.2 .^{7}$ The average risk ratio of 1.7 suggests a $70 \%$ improvement in cessation, and the confidence interval suggests that the outcome (cessation) is at least $30 \%$ higher in the treated versus the untreated (control/comparison) groups (table $1^{12-26}$ ). It appears that this intervention is at least as effective with ethnic minority women, notably African American women, as with white, non-Hispanic women. ${ }^{12-14}$ It is less effective, however, with more addicted smokers, ${ }^{121315}$ and it is not clear what additional interventions might be effective with these smokers.

\section{Steps for cessation counselling during pregnancy}

We use the "ask, advise, assess, assist, and arrange" steps as the basis for recommended counselling for pregnant women. The " $4 \mathrm{As}$ " (ask, advise, assist, and arrange) were developed by Glynn and Manley and recommended by the National Cancer Institute for counselling smokers in clinical practice. ${ }^{27}$ The AHCPR also adopted these steps in its original smoking guideline. ${ }^{8}{ }^{9}$ In the revised guideline, a fifth step is also recommended. ${ }^{10}$ Placed between the "advise" and "assist" steps is the "assess" step in which the willingness of smokers to make a quit attempt is assessed. We suggest a minimum time to perform each counselling step.
The AHRQ smoking cessation guideline panel update used studies of general populations to assess the impact of total contact time for this type of cessation intervention, using six time categories, ranging from zero to $>300$ minutes. The guideline panel concluded that there was a dose response effect up through the category 31-90 minutes, but that lengthier contact time did not improve rates of cessation. Yet, because of the relatively brief total contact time evaluated in the trials with pregnant women assessed by the guideline panel and the participants in the consensus conference, we recommend total contact time of 5-15 minutes plus self help materials. ${ }^{10}{ }^{11} \mathrm{~A}$ similar idea is expressed in the updated AHRQ guideline recommendation as "interventions that exceed minimal advice" - defined as $<3$ minutes. ${ }^{10}$

Many pregnant women are reluctant to disclose their smoking status at their first prenatal visit. Deception rates as high as $23 \%$ among Medicaid insured ${ }^{28}{ }^{29}$ and $14 \%$ among privately insured pregnant women ${ }^{30}$ have been biochemically confirmed. Non-disclosure can be reduced using the multiple choice question shown above in either written or oral formats. Tests of similar questions in both written and oral formats have improved disclosure as compared with the yes/no question typically used, "Do you smoke?". 31

While biochemical methods to validate smoking status are becoming more widely available and affordable - for example, cotinine dipsticks for urine-the acceptability of such testing is not known. Therefore, at present, we do not recommend biochemical testing as part of routine screening of all pregnant women for smoking. Anonymous testing for a period of 
Step 1: ASK

- Ask the patient about her smoking status

A. I have NEVER smoked, or I have smoked less than 100 cigarettes in my lifetime.

B. I stopped smoking BEFORE I found out I was pregnant, and I am not smoking now.

C. I stopped smoking AFTER I found out I was pregnant, and I am not smoking now.

D. I smoke some now, but I cut down on the number of cigarettes I smoke SINCE I found out I was pregnant.

E. I smoke regularly now, about the same as BEFORE I found out I was pregnant.

If patient responds to $B$ or $C$, reinforce her decision to quit, congratulate her on success in quitting, and encourage her to stay quit.

If patient responds $D$ or $E$, she should be classified as a smoker. Document smoking status on her clinic chart, and proceed to ADVISE, ASSESS, ASSIST and ARRANGE.

time could be useful in establishing the true prevalence of smoking in individual practices or clinics.

For patients indicating at intake that they have quit smoking since becoming pregnant, recognition and encouragement may be helpful in preventing relapse. This includes affirming their decision to quit, congratulating them on their success in quitting, describing the health benefits for them and their baby, and encouraging them to remain abstinent. ${ }^{89}$ In five randomised controlled trials, additional enhancements to this approach were not found to decrease the likelihood of relapse during pregnancy. ${ }^{7}$ More research is needed to identify and test innovative strategies that might build on these simple techniques and promote long term success of the spontaneous quitter.

For women who identify themselves as smokers at intake, clinicians should note this on their charts. Each clinician or facility should implement systems to identify and document systematically the smoking status of pregnant women. ${ }^{8-10}$ Findings from a meta-analysis of nine randomised clinical trials indicated that implementing a clinical system greatly increases the rate at which clinicians intervene with their patients who smoke. ${ }^{89}$

Step 2: ADVISE-1 minute

- Provide clear, strong advice to quit with personalised messages about the impact of smoking and quitting on mother and fetus.

The guideline recommends that clinicians urge every smoker to quit in "a clear, strong and personalised manner." ${ }^{-10}$ For pregnant women, this should include discussions of the multiple risks to mother and fetus and infant from maternal smoking, and the benefits of quitting for both. Advice should stress that quitting smoking is one of the most important actions a woman can take to improve the outcome of her pregnancy, and that specific harms for her and the baby can be reduced by quitting. Women who stop smoking before becoming pregnant or during the first four months of pregnancy have the same risk of having a low birth weight baby as women who never smoked. ${ }^{32}$

It should also be noted that smoking cessation has immediate health benefits for women of all ages, whether or not they suffer from smoking related diseases. Not only does cessation before or during pregnancy reduce the risk of maternal complications and adverse pregnancy outcomes, it can also, if sustained, benefit the woman and her health status long term.

\section{Step 3: ASSESS}

- Assess the willingness of the patient to make a quit attempt within the next 30 days.

The revised AHRQ guideline recommends that clinicians assess a patient's willingness to make a quit attempt before proceeding to the "assist" and "arrange" steps. ${ }^{10}$ Specifically, each pregnant smoker should be asked if she is willing to make a quit attempt within the next 30 days. One approach to this assessment is: "Quitting smoking is one of the most important things you can do for your health and your baby's health. If we can give you some help, are you willing to give it a try?" If she is willing to make a quit attempt at this time, the provider should move to step 4 . For patients who are unwilling to attempt cessation, quitting advice, assessment and assistance can be offered in future visits in much the same way they are with smokers who are ready to quit. Most pregnancy tailored self help materials contain special messages to build motivation and confidence in support of a cessation attempt.

The benefits of "cutting down" are difficult to measure or verify, so women who ask if cutting down is helpful should be reinforced for taking this step, but reminded that quitting entirely brings the best results for their own and their baby's health.

Step 4: ASSIST-3 minutes +

- Provide pregnancy specific, self help smoking cessation materials.

- Suggest and encourage the use of problem solving methods and skills for cessation.

- Arrange social support in the smoker's environment.

- Provide social support as part of the treatment. 
Analysis of the interventions tested with pregnant women (table 1) indicate the effectiveness of providing pregnancy specific patient education materials. ${ }^{17}$ Studies with general samples of smokers also suggest that teaching problem solving methods and skills, ${ }^{8-10}$ arranging social support from family, friends and co-workers, ${ }^{10}$ and receiving support from the clinician are helpful, ${ }^{8-10}$ whereas contingency contracting, relaxation/ breathing, cigarette fading, and exercise/fitness content are not. ${ }^{8-10}$

The following specific strategies are recommended as part of providing assistance to pregnant women who smoke:

Provide pregnancy specific, self help smoking cessation materials - An early study showed that pregnancy related messages significantly increased the likelihood of cessation. ${ }^{17}$ The cessation rate of the group receiving the brief counselling with a pregnancy tailored manual was twice that of the group receiving the brief counselling with a general cessation manual. ${ }^{17}$ Since then, all of the tested interventions have used pregnancy specific information (table 1). Materials should be relevant to pregnancy and prenatal care as described above. Numerous self help quitting guides tailored for pregnancy have been tested and found effective with pregnant smokers of varied demographic groups (for example, ethnicity, income, education). Information on pregnancy materials may be found in the prenatal smoking cessation combined health information database on the web at http://chid.nih.gov.

Problem solving - Problem solving includes recognition of danger situations, relapse prevention, coping and stress management, and basic information about addiction and the time course of withdrawal. ${ }^{8-10}$

Social support in the smoker's environment-The counsellor should prompt support seeking and help the patient develop support solicitation skills as approaches to gaining outside support (for example, from family, friends, and co-workers) for her decision to make a quit attempt. ${ }^{10}$

Social support as part of treatment-Social support from the counsellor means that the counsellor is encouraging, communicates caring and concern, and encourages the patient to talk about the process of quitting. ${ }^{8} 9$

Addiction in the general population of smokers is addressed in the guideline by strong recommendations for the use of pharmacotherapies (for example, buproprion and nicotine replacement therapy). Nicotine replacement therapy as an adjunct to counselling has been shown to increase cessation rates. ${ }^{8-10}$ More recently, buproprion, in conjunction with nicotine replacement plus counselling, has also shown a strong positive effect in a sample of non-depressed smokers. ${ }^{33}$ To date, no study has evaluated the efficacy and safety of these therapies during pregnancy. Thus, the evidence, at this point, is not conclusive about the ratio of potential harm to benefit for use during pregnancy ${ }^{8-1034-36}$ and supports the need to consider pharmacotherapies only after psychosocial intervention has failed. ${ }^{9}{ }^{10}$
More research is needed on this topic before specific recommendations can be made about the use of pharmacotherapies during pregnancy. ${ }^{37}$ Optimally, smokers can be treated with these pharmacotherapies before conception. ${ }^{1038}$

Research findings indicate that the type of behavioural counselling assistance described above may not be sufficient for pregnant women who are heavy smokers. While the research is not clear on the best intensive behavioural treatment for pregnant, heavy smokers, referral to the types of counselling recommended as more effective in the AHRQ Guideline should be considered.

\section{Step 5: ARRANGE-1 minute +}

- Periodically assess smoking status and, if she is a continuing smoker, encourage cessation.

While quitting early in pregnancy is best, smoking cessation brings benefits throughout the pregnancy for the mother, fetus, and infant. Smoking status should be monitored throughout pregnancy providing opportunities to congratulate and support success, reinforce steps taken towards quitting, and advise those still considering a cessation attempt.

\section{Conclusions}

In summary, data from randomised clinical trials and from the meta-analyses used to update the AHCPR clinical practice guideline on smoking cessation show that a 5-15 minute cessation counselling intervention delivered by a trained provider, in conjunction with the provision of pregnancy specific self help materials, can achieve a significant increase in cessation during pregnancy. ${ }^{10}$ Thus, we recommend these evidence based procedures be adopted by all prenatal care providers.

We believe that the use of this intervention is feasible in most office or clinic settings without inhibiting other important aspects of prenatal care or disrupting patient flow. If implemented widely, this approach has the potential to achieve an important reduction in a number of adverse maternal, infant, and pregnancy outcomes and to reduce associated, excess health care costs. ${ }^{39-42}$

The authors wish to thank C Tracy Orleans for her valuable review and comment on this paper. Attendees at the 1998 Consensus Workshop on Smoking Cessation in Pregnancy: (in alphabetical order): E Kathleen Adams, PhD, Department of alphabetical order): E Kathleen Adams, PhD, Department of Health, Emory University; Trina M Anglin, MD, PhD, Maternal and Child Health Bureau, Health Resources and Services Administration (HRSA), Department of Health and Human Services (DHHS); Dianne C Barker, Barker Bi-Coastal Health Consultants, Calabassas, CA; Doris M Barnette ACSW, Department of Health and Human Services, Health Resources and Services Administration, Rockville, MD:Carolyn Aoyama, CNM, MPH, Bureau of Primary Health Care, HRSA, DHHS; Elaine Bratic Arkin, Consultant; Ashley Coffield, Partnership for Prevention; Carlo C DiClemente, PhD, Department of Psychology, University of Maryland-Baltimore County; Karen M Emmons, PhD, Cancer Epidemiology and Control, Dana-Farber Cancer Institute; Roselyn Payne Epps, MD, MPH, National Cancer Institute, National Institutes of Health MPH, National Cancer Institute, National Institutes of Health (NIH), DHHS; Daniel H Ershoff, DrPH, Southern California Kaiser-Permanente; Robert L Goldenberg, MD, Smoke-Free Families National Program Office, Department of Obstetrics and Gynecology, University of Alabama, Birmingham, AL; PhD, National Heart, Lung, and Blood Institute, NIH, DHHS; 
Ruth R Karimi, Consultant; Lorraine V Klerman, DrPH, Smoke-Free Families Program, University of Alabama at and Child Health Programs; Helen E McIlvain, PhD, Department of Family Practice, University of Nebraska Medical Center; Cathy L Melvin, PhD, MPH, Program Services and Development Branch, Division of Reproductive Health, CDC, Atlanta, GA; Patricia Dolan-Mullen, DrPH, Center for Health Promotion Research and Development, School of Public Health, University of Texas Health Sciences Center, Houston, TX; C Tracy Orleans, PhD, Research and Evaluation Unit, Robert Wood Johnson Foundation, Princeton, NJ; Rebecca Pasternik-Ikard, JD, MS, RN, Managed Care Organization Operations, Oklahoma Health Care Authority (OHCA); Susan L Prows, PhD, MPH, Department of Public nership for Prevention; Abby C Rosenthal, MPH, National nership for Prevention; Abby C Rosenthal, MPH, National Technical Assistance Office, Addressing Tobacco in Managed versity of Vermont; Gary Stuart, MEd, National Center for versity of Vermont; Gary Stuart, MEd, National Center for
Chronic Disease Prevention and Health Promotion, Centers for Chronic Disease Prevention and Health Promotion, Centers for
Disease Control and Prevention, DHHS; Jana Webb, RN, Disease Control and Prevention, DHHS; Jana Webb, RN,
Medical Professional Services, OHCA; H Pennington Medical Professional Services, OHCA; H Pennington
Whiteside, MSPH, Smoke-Free Families National Program Whiteside, MSPH, Smoke-Free Families National Program Alabama, Birmingham, AL; Richard A Windsor, PhD, MPH Smoke-Free Families National Program Office, University of Alabama, Birmingham, AL.

1 DiFranza JR, Lew RA. Effect of maternal cigarette smoking on pregnancy complications and sudden infant death syndrome. F Fam Pract 1995;40:385-94.

2 Castles A, Adams EK, Melvin CL, Kelsch C, Boulton ML. Effects of smoking during pregnancy. Five meta-analyses. Am f Prev Med 1999;16:208-15.

3 Windsor RA, Orleans CT. Guidelines and methodological standards for smoking cessation intervention research among pregnant women: improvir

4 Dolan-Mullen P, Ramirez G, Groff JY. Obstetrics: a meta-analysis of randomized trials of prenatal smoking cessation interventions. Am $\mathcal{f}$ Obstet Gynecol 1994; 171:1328-34.

5 Windsor RA, Boyd NR, Orleans CT. A meta-evaluation of smoking cessation intervention research among pregnant
women: improving the science and art. Health Educ Res women: improvin

6 Dolan-Mullen P. Essential elements of state-of-the-art smoking cessation interventions for pregnant smokers based on available research evidence, meta-analysis and AHCPR smoking cessation clinical practice guideline. In Summary: consensus on smoking cessation in pregnancy, www.smokefreefamilies.uab.edu/web-ccs.doc

7 Mullen PD. Maternal smoking during pregnancy and evidence-based intervention to promote cessation. In: Spangler JG, ed. Primary care: clinics in office practice (tobacco use and cessation). Philadelphia: WB Saunders, 1999;26:577-89.

8 Fiore MC, Bailey WC, Cohen SJ, et al. Smoking cessation. Clinical Practice Guideline No 18. Rockville, Maryland:
US Department of Health and Human Services, Public Health Service, Agency for Health Care Policy and Research, April 1996. (AHCPR Publication No 96Research, April 1996. (AHCPR
0692.); < http://text.nlm.nih.gov>

9 Agency for Health Care Policy and Research. AHCPR smoking cessation clinical practice guideline. FAMA 1996; 275:1270-80.

10 Fiore MC, Bailey WC, Cohen SJ. Treating tobacco use and dependence: a clinical practice guideline. Rockville, Maryland: US Department of Health and Human Services. A Public Health Service report. May 2000.

11 Consensus Workshop on Smoking Cessation during Pregnancy. Sponsored by the Robert Wood Johnson Foundation and the Smoke-Free Families Program in collaboration with the Health Resources and Services Administration and the Centers for Disease Control and Prevention. Rockville, Maryland, 9-10 April 1998.

12 Ershoff DH, Mullen PD, Quinn VP. A randomized trial of serialized self-help smoking cessation program for pregnant women in an HMO. Am f Public Health 1989;79:182-7.

13 Windsor RA, Lowe JB, Perkins LL, et al. Health education methods for pregnant smokers: its behavioral impact and cost benefit. Am ₹ Public Health 1993;83:201-6.

14 Woodby LL, Windsor RA, Snyder SW, et al. Predictors of smoking cessation during pregnancy. Addiction 1999; 94:283-92.

15 Hartmann KE, Thorp JM, Pahel-Short L, et al. A randomized controlled trial of smoking cessation intervention in pregnancy in an academic clinic. Obstet Gynecol 1996;87:621-6.

16 Sexton M, Hebel JR. A clinical trial of change in maternal smoking and its effects on birth weight. $7 A M A 1984$ 251:911-5.

17 Windsor RA, Cutter G, Morris J, et al. Effectiveness of smoking cessation methods for smokers in public health maternity clinics: a randomized trial. Am f Public Health 1985;75:1389-92.
18 Burling TA, Bigelow GE, Robinson JC, et al. Smoking during pregnancy: reduction via objective assessment and $2: 31-40$.

19 Hjalmarson AIM, Hahn L, Svanberg B. Stopping smoking in pregnancy: effect of a self-help manual in controlled trial. Br F Obstet Gynaecol 1991;98:260-4.

20 Price JH, Desmond SM, Roberts SM, et al. Comparison of three antismoking interventions among pregnant women in an urban setting: a randomized trial. Psychological Reports 1991;68:595-604.

21 O'Connor AM, Davies BL, Dulberg CS, et al. Effectiveness of a pregnancy smoking cessation program. F Obstet Gyneof a pregnancy smoking cessation pro
col Neonatal Nurs 1992;21:385-92.

22 Petersen L, Handel J, Kotch SM, et al. Smoking reduction during pregnancy by a program of self-help and clinical support. Obstet Gynecol 1992;79:924-30.

23 Secker-Walker RH, Solomon LJ, Flynn BS, et al. Individualized smoking cessation counseling during prenatal and early postnatal care. Am f Obstet Gynecol 1994;171:1347-55.

24 Kendrick JS, Zahniser SC, Miller N, et al. Integrating smoking cessation into routine public prenatal care: the smoking cessation in pregnancy project. Am $\mathcal{F}$ Public Health 1995;85:217-22.

25 Walsh RA, Redman S, Brinsmead MW, et al. A smoking cessation program at a public antenatal clinic. Am $\mathcal{F}$ Public Health 1997:87:1201-4.

26 Gielen AC, Windsor R, Faden RR, et al. Smoking cessation among pregnant women in an urban clinic: evaluation of a community health worker intervention. Health Education Research: Theory and Practice 1997;12:247-54.

27 Glynn TJ, Manley MW. How to help your patients stop smoking: a National Cancer Institute manual for physicians, Washington, DC: Smoking and Tobacco Control Program, Division of Cancer Prevention, National Cancer Institute, US Dept of Health and Human Services, November 1990. (NIH publication 90-3064.)

28 Windsor RA. Health care delivery issues and systems. Presentation at consensus workshop on smoking cessation in pregnancy, Health Resources and Services Administration, Rockville, Maryland, 9-10 April 1998.

29 Windsor RA, Woodby LA, Miller T, et al. Effectiveness of AHCPR practice recommendations and patient education methods for pregnant smokers in Medicaid maternity care. Am f Obstet Gynecol 2000;182:68-75.

30 Mullen PD, Carbonari JP, Tabak ER, et al. Improving the disclosure of smoking by pregnant women. Am f Obstet Gynecol 1991;165:409-13.

31 Kharazi M, Epstein D, Hopkins B, et al. Evaluation of four maternal smoking questions. Public Health Reports 1999; 114:60-9.

32 US Department of Health and Human Services. The health benefits of smoking cessation. A report of the Surgeon General. Rockville, Maryland: US Department of Health and Human Services, Public Health Service, Centers for Disease Control, Center for Chronic Disease Prevention
and Health Promotion, Office on Smoking and Health, 1990. (DHHS Publication No. (CDC) 90-8416.)

33 Jorenby DE, Leischow SJ, Nides MA, et al. A controlled trial of sustained release buproprion, a nicotine patch, or both for smoking cessation. $N$ Engl f Med 1999;340:685-91.

34 Wisborg K, Jespersen L, Henriksen TB, et al. Nicotine patches to pregnant smokers - a randomized study. Presented Research on Nicotine and Tobacco, Copenhagen, DenResearch on Nicotine
mark, August 23, 1998.

35 Oncken CA, Hatsukami DK, Lupo VR, et al. Effects of short-term use of nicotine gum in pregnant smokers. Clin Pharmacol Ther 1996;59:654-61.

36 Benowitz NL, Pinney J. Nicotine preparations in smoking. In: Korting HC, Schafer-Korting M, eds. The benefit/risk ratio. Boca Raton: CRC Press, 1999:307-18.

37 Workshop on the Use of Pharmacotherapies for Smoking Cessation in Pregnancy. Sponsors: National Institute for Child Health and Human Development and the SmokeFree Families Program. Rockville, Maryland, 19 May 1999.

38 Public Health Service Expert Panel on the Content of Prenatal Care. Caring for our future: the content of prenatal care. Report of the Public Health Service Expert Panel on the content of prenatal care. Washington, DC: Public Health Service/US Department of Health and Human Services, 1989.

39 Windsor RA, Warner KE, Cutter GR. A cost-effectiveness analysis of self-help methods for pregnant women. Public Health Rep 1988;103:83-8.

40 Marks JS, Koplan JP, Hogue CJ, et al. A cost-benefit analysis of smoking cessation for pregnant women. Am $\mathcal{F}$ Prev Med 1990;6:282-9.

41 Ershoff DH, Quinn VP, Mullen PD, et al. Pregnancy and medical cost outcomes of a self-help prenatal smoking cessation program in an HMO. Public Health Rep 1990; 105:340-7.

42 Melvin CL, Adams EK, Miller V. Costs of smoking during pregnancy: development of the maternal and child health smoking attributable mortality, morbidity and economic costs (MCHSAMMEC) software. Tobacco Control 2000; 9(suppl III):iii12-15. 